\title{
openheart Glycaemic control and excess risk of major coronary events in patients with type 2 diabetes: a population-based study
}

\author{
Mauro Tancredi, ${ }^{\oplus, 2}$ Annika Rosengren, ${ }^{1}$ Ann-Marie Svensson, ${ }^{1,3}$ Aldina Pivodic,, 4 \\ Soffia Gudbjörnsdottir, ${ }^{1}$ Hans Wedel, ${ }^{6}$ Marcus Lind ${ }^{1,2}$
}

\begin{abstract}
- Additional material is published online only. To view please visit the journal online (http://dx.doi.org/10. 1136openhrt-2018-000967).
\end{abstract}

To cite: Tancredi M, Rosengren A, Svensson A-M, et al. Glycaemic control and excess risk of major coronary events in patients with type 2 diabetes: a population-based study. Open Heart 2019;6:e000967. doi:10.1136/ openhrt-2018-000967

Received 14 November 2018 Revised 18 April 2019 Accepted 6 May 2019
Check for updates

(C) Author(s) (or their employer(s)) 2019. Re-use permitted under CC BY-NC. No commercial re-use. See rights and permissions. Published by BMJ.

For numbered affiliations see end of article.

Correspondence to Dr Mauro Tancredi; mautanc@ hotmail.com

\section{ABSTRACT}

Objective The purpose of the study was to investigate the excess risk of acute myocardial infarction (AMI) and death from coronary artery disease (coronary heart disease, $\mathrm{CHD}$ ) in relation to age, level of glycaemic control and renal complications in patients with type 2 diabetes. Methods A total of 431579 patients with type 2 diabetes mellitus registered in the Swedish National Diabetes Register from 1 January 1998 to 31 December 2012, and 2173620 controls from the general population were included. Cox regression was used to study the excess risk of AMl and CHD.

Results During follow-up of 5.1 years in the diabetes group and 5.4 years in the control group, 36124 (8.4\%) and 115712 (5.3\%) CHD events were registered, with corresponding incidence rates/1000 person-years of $14.64(95 \% \mathrm{Cl} 14.49$ to 14.79$)$ and $8.73(95 \% \mathrm{Cl} 8.68$ to 8.78), respectively. The HR after adjustment for sex and age was 1.67 (1.65-1.69) which was reduced to 1.42 (1.41-1.44) with further adjustment for level of education, country of birth, diabetes duration and comorbidities. The multivariable-adjusted HR for AMI and CHD death with a time-updated glycated haemoglobin level of $6.9 \%$ or lower $(\leq 52 \mathrm{mmol} / \mathrm{mol})$ together with normoalbuminuria and estimated glomerular filtration rate $\geq 60 \mathrm{~mL} / \mathrm{min}$ for patients with diabetes compared with controls was 0.95 (95\% Cl 0.92 to $0.98, \mathrm{p}<0.001)$.

Conclusions In this study, the excess risk of $\mathrm{AMI}$ and $\mathrm{CHD}$ death was higher for patients with type 2 diabetes compared with controls but converged to that in the general population in patients with on-target $\mathrm{HbA} 1 \mathrm{c}$ levels and without renal complications.

\section{INTRODUCTION}

The number of adults with diabetes in the world increased from 108 million in 1980 to 422 million in 2014. ${ }^{1}$ Diabetes mellitus is a major cause of illness and premature death in most countries. ${ }^{2}$ Cardiovascular disease (CVD) is the major contributor to excess risk of death in patients with diabetes ${ }^{3}$ and responsible for more than $65 \%$ of deaths. ${ }^{4}$

In particular, diabetes is associated with increased risk of coronary heart disease

\section{Key questions}

What is already known about this subject?

- Cardiovascular disease is the principal cause of death and disability among patients with type 2 diabetes mellitus.

What does this study add?

- In this population-based study, it was observed that the excess risk for major coronary events was higher in patients with type 2 diabetes compared with controls but converged to that in the general population in those with time-updated on-target $\mathrm{HbA} 1 \mathrm{C}$ levels and without renal complications.

- Furthermore, the excess risk of major coronary events at any age was higher for women with type 2 diabetes compared with men.

How might this impact on clinical practice?

- Earlier detection of diabetic nephropathy and optimal glycaemic control are required as an effective strategy in preventing major coronary events.

(CHD). ${ }^{5} \mathrm{~A}$ meta-analysis of 102 prospective studies ${ }^{5}$ including individual data from nearly 700000 persons (baseline years: 19602007) showed that diabetes confers about a twofold excess risk for CHD and similar HRs for coronary events ${ }^{6}$ compared with a large population-based prospective study conducted on 500000 participants (baseline years: 2006-2010). Additionally, diabetes was more strongly related to fatal than non-fatal myocardial infarction. HRs for CHD were higher for women than men and in younger than older individuals. Among those with known diabetes at baseline, poor glycaemic control, measured by fasting blood glucose, was associated with higher risk. However, the data underlying from this meta-analysis are now relatively outdated and may not accurately reflect diabetes outcomes in a more contemporary setting. Recent data ${ }^{7}$ conducted in type 1 and type 2 diabetes 
individuals from the Swedish National Diabetes Register (NDR) show that mortality and the incidence of cardiovascular outcomes declined substantially among patients with diabetes. Accordingly, more recent data are needed to analyse these issues.

Previous studies ${ }^{5}$ have shown that type 2 diabetes confers a stronger excess risk of CVDs in women than men, with women having $27 \%$ and $44 \%$ higher relative risks of stroke and $\mathrm{CHD}$, respectively, compared with men. The mechanisms underpinning these sex differences are not fully understood. Suggested explanations include a higher risk-factor burden, more extensive coronary artery disease, as well as hormonal imbalances, suboptimal treatment targets and silent ischaemia. ${ }^{9}$

Although excess risk for coronary events in patients with type 2 diabetes has been shown to vary with age, ${ }^{10}$ $\operatorname{sex}^{58}$ and glycaemic control, ${ }^{11}$ few have been adequately powered to the overall risk for acute myocardial infarction (AMI) or CHD death in patients with type 2 diabetes in relation to glycaemic control and renal complications. In this study, we investigated the contemporary excess risk of CHD associated with type 2 diabetes in a nationwide registry of adults with diabetes.

\section{PARTICIPANTS AND METHODS}

To access population-based data on patients with type 2 diabetes we used the Swedish NDR. The NDR has been described previously. ${ }^{12}$ Type 2 diabetes was defined as treatment with diet with or without oral glucose-lowering agents, or insulin with or without oral glucose-lowering agents. The latter category only applied to patients $\geq 40$ years at diabetes diagnosis.

Patients with at least one entry in the NDR from 1 January 1998 to 31 December 2012 were included. For $433618(91.5 \%)$ patients with type 2 diabetes, five age, sex and county-matched controls were randomly selected from the general population in Sweden. ${ }^{13}$ Because of the large number of controls required, only four matched controls were available for $22012(4.6 \%)$ patients with type 2 diabetes, three controls for $2124(0.5 \%)$, two controls for $368(0.1 \%)$ and one control for $302(0.1 \%)$. For $15622(3.3 \%)$ patients with type 2 diabetes no matched controls were available.

Information on comorbidities and cause-specific mortality for cases and controls was retrieved by linkage to the Swedish Patient Register and Cause of Death Register. Education and country of birth were retrieved from the Longitudinal Integration Database for Health Insurance and Labour Market studies. ${ }^{14}$ Education was categorised as low (compulsory only), intermediate and high (university or similar). Country of birth was categorised as Sweden or other. The currently used cohort has also been linked with the Swedish Prescribed Drug Register which included information from the entire Swedish Population after July $2005 .^{15}$

Patients and controls were followed from baseline until death or 31 December 2013. In total, 42211 (8.9\%) patients with type 2 diabetes and 90034 (4.0\%) matched controls had experienced AMI before index date and, therefore, were excluded. Further, 12 patients and 138 controls were excluded due to inconsistent vital status data, leaving 431579 (91\%) patients with type 2 diabetes and 2173620 (96\%) controls in the analyses.

\section{Outcomes}

Primary outcome during follow-up was major coronary events (AMI and death from CHD). The Inpatient Register provides nationwide coverage of all inpatient admissions from 1987 onwards. International Classification of Diseases (ICD) codes were retrieved for AMI, CHD, hospitalisation for heart failure, atrial fibrillation, stroke, cancer diagnoses, renal dialysis and transplantation after 1987. Dates and diagnoses for death from cardiovascular, cancer, diabetes, external and all other causes were retrieved from the cause of death register. For ICD codes, see the online supplementary appendix.

AMI and CHD death rates were assessed across categories of updated mean glycosylated haemoglobin (HbA1c) levels ${ }^{16}$ to compare rates of coronary events in patients and matched controls according to glycaemic control. HbAlc analyses were performed according to the International Federation of Clinical Chemistry standard measured in $\mathrm{mmol} / \mathrm{mol}$ and converted to levels according to the National Glycohemoglobin Standardization Program for dual reporting. ${ }^{17}$

Analysis of AMI and CHD death were also performed for two renal variables: (1) normoalbuminuria, microalbuminuria, macroalbuminuria and stage 5 chronic kidney disease (CKD), and (2) estimated glomerular filtration rate (eGFR) 15 to $<30,30$ to $<60,60$ to $<90$ and $\geq 90 \mathrm{~mL} / \mathrm{min}$ and stage $5 \mathrm{CKD}$. Stage $5 \mathrm{CKD}$ was defined as need for dialysis or eGFR $<15 \mathrm{~mL} / \mathrm{min}$.

Microalbuminuria was defined as two positive tests from three samples taken within 1 year, with an albumin/ creatinine ratio of $3-30 \mathrm{mg} / \mathrm{mmol}(30-300 \mathrm{mg} / \mathrm{g})$ or U-albumin of 20-200 $\mu \mathrm{g} / \mathrm{min}(20-300 \mathrm{mg} / \mathrm{L})$. Macroalbuminuria was defined as albumin/creatinine ratio $>30$ $\mathrm{mg} / \mathrm{mmol}$ and eGFR was calculated using the Chronic Kidney Disease Epidemiology Collaboration (CKD-EPI) ${ }^{18}$

Systolic blood pressure (SBP) was the mean value of two supine readings with a cuff of appropriate size and after at least 5 min of rest. Low-density lipoprotein (LDL), high-density lipoprotein (HDL) and total cholesterol were measured in $\mathrm{mmol} / \mathrm{L}$.

\section{Statistical analysis}

Crude event rates are given as events per 1000 patientyears, with $95 \%$ CIs and unadjusted incidence rate ratios between patients with type 2 diabetes versus controls estimated by exact Poisson regression. Survival analyses were performed using Cox regression adjusted for sex and time-updated (value recorded closest to the time preceding each event) age in model 1, additionally including time-updated diabetes duration (assuming 
0 year for controls and 1 year corresponding to 10th percentile, 4 years to 25 th percentile, 8 years to 50 th percentile, 13 years to 75 th percentile and 19 years to 90 th percentile in the distribution of time-updated diabetes duration; 8 years of diabetes duration was interpreted as main analysis) as the continuous covariate in model 2, and further adjusted for education level, country of birth and comorbidities prior to baseline (CHD, atrial fibrillation, heart failure, stroke, valve disease and cancer) in model 3. Model 3 (main model) and, respectively, model 3a for males and model $3 \mathrm{~b}$ for females were also used to evaluate the association between different outcomes and time-updated $\mathrm{HbAlc}$ categories, time-updated albuminuria categories and time-updated eGFR categories in patients with type 2 diabetes versus controls. The effect per $10 \mathrm{mmol} / \mathrm{mol}$ higher updated mean HbAlc and time-updated HbAlc categories on events in diabetes population was evaluated separately for men and women, performing model 1-3 as per above, and further adjusting for 3A) time-updated mean SBP, time-updated mean BMI, time-updated smoking and time-updated status on blood pressure lowering medication, 3B) time-updated mean HDL, time-updated mean LDL, time-updated status on lipid lowering medication, 3C) time-updated insulin method, 3D) time-updated albuminuria categories. Interactions for diabetes with sex and prespecified years $(<2005$ and $\geq 2005$ ) were also investigated. In these analyses, the time-updated baseline comorbidities prior to 2005 were included in adjustments. Analyses of AMI and CHD death by renal disease status were performed using methods similar to those for time-updated mean HbA1c. The proportional hazards assumption was fulfilled. Post-hoc analysis studying baseline HbA1c instead of time-updated mean HbAlc was performed, and analysis of AMI events alone excluding death due to CHD events.

All tests were two tailed and conducted at the 0.05 significance level. All analyses were performed using SAS software V.9.4 (SAS Institute).

\section{RESULTS}

\section{Baseline characteristics of population}

Among 431579 patients with type 2 diabetes and 2173620 controls, the proportion of women and the distribution according to age were similar. However, fewer patients with diabetes compared with controls were born in Sweden and had a university education or higher. Baseline characteristics of the two groups are shown in table 1. All coexisting cardiovascular conditions were more common among patients with diabetes than controls. The mean HbAlc at baseline in the diabetes group was $7.1 \%(54.4 \mathrm{mmol} /$ $\mathrm{mol}$ ), mean diabetes duration was 5.5 years, mean blood pressure was 140/79 mm Hg, mean low-density lipoprotein was $3.0 \mathrm{mmol} / \mathrm{L}$ and $84.4 \%$ were non-smokers.

\section{Rates of coronary events in individuals with type 2 diabetes versus controls}

The unadjusted rates of major coronary events stratified according to baseline age and sex are shown in table 2.
Table 1 Baseline characteristics of patients with type 2 diabetes and matched controls from the general population

\begin{tabular}{|c|c|c|}
\hline & $\begin{array}{l}\text { Controls } \\
n=2173620\end{array}$ & $\begin{array}{l}\text { All type } 2 \text { diabetes } \\
\mathrm{n}=431579\end{array}$ \\
\hline Men & $1170663(53.9 \%)$ & $234556(54.3 \%)$ \\
\hline Age (years) & $\begin{array}{l}64.7(12.6) \\
n=2173620\end{array}$ & $\begin{array}{l}65.0(12.7) \\
n=431579\end{array}$ \\
\hline Born in Sweden & $1902246(87.5 \%)$ & $353441(82.0 \%)$ \\
\hline \multicolumn{3}{|l|}{ Education } \\
\hline Low & $770057(36.1 \%)$ & $182183(43.3 \%)$ \\
\hline Mid & $845048(39.6 \%)$ & $169656(40.4 \%)$ \\
\hline High & $520240(24.4 \%)$ & $68508(16.3 \%)$ \\
\hline \multicolumn{3}{|l|}{ Variables in the NDR only } \\
\hline $\begin{array}{l}\mathrm{HbA} 1 \mathrm{c}(\mathrm{mmol} / \mathrm{mol} \text {, } \\
\text { IFCC) }\end{array}$ & & $\begin{array}{l}54.4(15.0) \\
\mathrm{n}=383878\end{array}$ \\
\hline HbA1c (\%, NGSP) & & $\begin{array}{l}7.13(1.37) \\
\mathrm{n}=383878\end{array}$ \\
\hline Diabetes duration & & $\begin{array}{l}5.50(7.06) \\
n=382414\end{array}$ \\
\hline $\begin{array}{l}\text { Body mass index } \\
\left(\mathrm{kg} / \mathrm{m}^{2}\right)\end{array}$ & & $\begin{array}{l}29.7(5.4) \\
n=324054\end{array}$ \\
\hline Cholesterol (mmol/L) & & $\begin{array}{l}5.10(1.10) \\
n=260743\end{array}$ \\
\hline $\begin{array}{l}\text { HDL cholesterol } \\
(\mathrm{mmol} / \mathrm{L})\end{array}$ & & $\begin{array}{l}1.28(0.39) \\
\mathrm{n}=229758\end{array}$ \\
\hline $\begin{array}{l}\text { LDL cholesterol } \\
(\mathrm{mmol} / \mathrm{L})\end{array}$ & & $\begin{array}{l}2.98(0.96) \\
n=222187\end{array}$ \\
\hline $\begin{array}{l}\text { Systolic blood } \\
\text { pressure (mm Hg) }\end{array}$ & & $\begin{array}{l}140.4(18.2) \\
n=369273\end{array}$ \\
\hline $\begin{array}{l}\text { Diastolic blood } \\
\text { pressure (mm Hg) }\end{array}$ & & $\begin{array}{l}78.9(9.8) \\
n=369273\end{array}$ \\
\hline Smoking & & $53911(15.6 \%)$ \\
\hline \multicolumn{3}{|c|}{ Registrations in the IPR prior to baseline } \\
\hline $\mathrm{AF}(148)$ & $104426(4.8 \%)$ & $33474(7.8 \%)$ \\
\hline CHD (I20-I25) & $77022(3.5 \%)$ & $31853(7.4 \%)$ \\
\hline HF (I50) & $48208(2.2 \%)$ & $21368(5.0 \%)$ \\
\hline $\begin{array}{l}\text { Valve disease (105- } \\
\text { 109, I34-136) }\end{array}$ & $31704(1.5 \%)$ & $8349(1.9 \%)$ \\
\hline Stroke (I61-I64) & 74137 (3.4\%) & $25269(5.9 \%)$ \\
\hline Cancer (C00-C97) & $182757(8.4 \%)$ & $38748(9.0 \%)$ \\
\hline
\end{tabular}

$\mathrm{AF}$, atrial fibrillation; $\mathrm{CHD}$, coronary heart disease; HDL, high-density lipoprotein; HF, heart failure; LDL, low-density lipoprotein; NDR, National Diabetes Register.

Overall coronary event rates per 1000 person-years were 14.6 among persons with type 2 diabetes (36 124 of 431 579 patients, $8.4 \%$ ) and 8.7 among controls (115 172 of 2173620 patients, 5.3\%). In men with type 2 diabetes, coronary event rates were 16.12 (95\% CI 15.90 to 16.34 ) per 1000 person-years (21 343 of 234556 patients, 9.1\%) as compared with 10.03 (95\% CI 9.96 to 10.10) among controls (71 180 of 1170663 patients, 6.1\%). Coronary event rates in women with type 2 diabetes were 12.93 (95\% CI 12.72 to 13.14 ) per 1000 person-years (14 781 of 197023 patients, $7.5 \%)$ as compared with 7.22 (95\% 


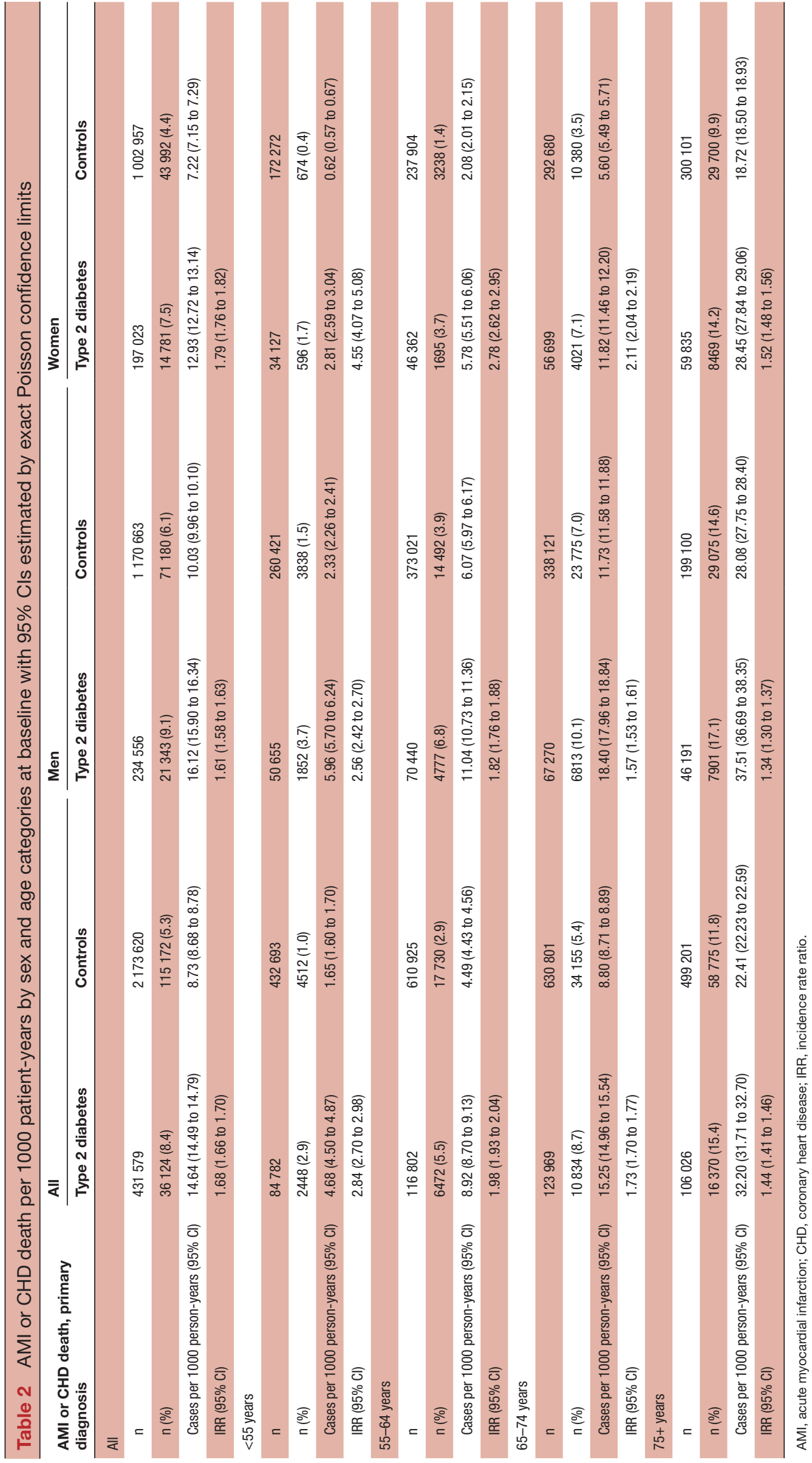




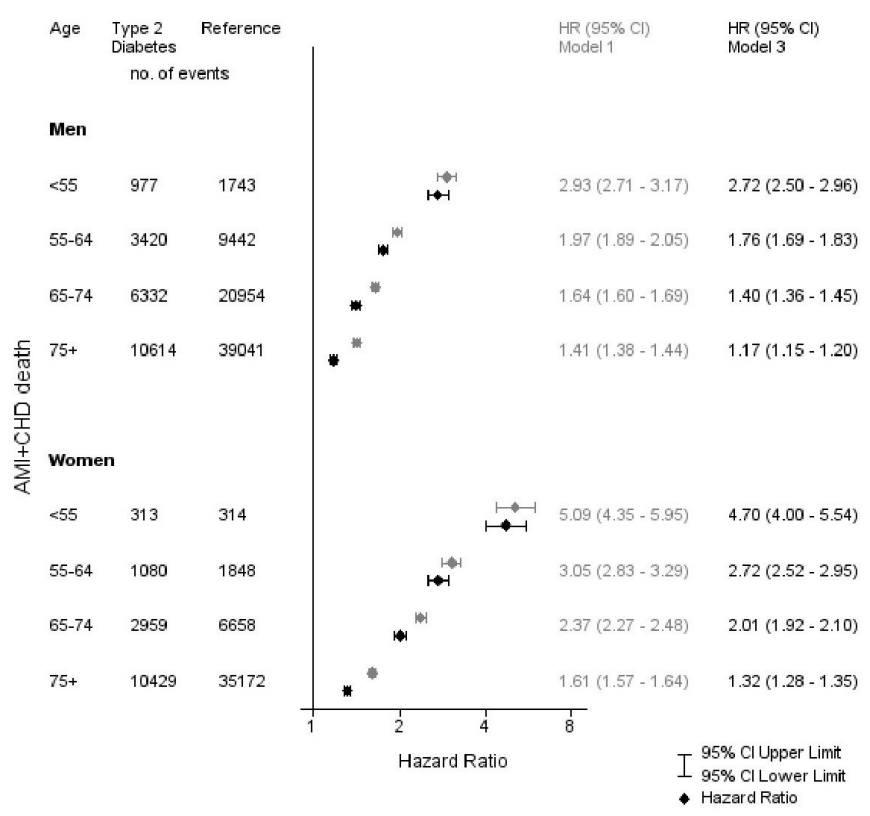

Figure 1 Adjusted HRs for acute myocardial infarction (AMI) and coronary heart disease (CHD) death, according to age category in men and women, in models 1 and 3.

CI 7.15 to 7.29) among controls (43992 of 1002957 patients, $4.4 \%)$.

\section{Relative risk for coronary events in the type 2 diabetes population versus controls}

In Cox regression analyses, the HR for AMI and death from CHD among persons with type 2 diabetes versus controls was 1.67 (95\% CI 1.65 to 1.69) with adjustment for sex and time-updated age, 1.57 (95\% CI 1.55 to 1.59) with adjustment for 8 years' diabetes duration and 1.42 (95\% CI 1.41 to 1.44 ) with additional adjustment for country of birth, education level, diabetes duration and comorbidities at baseline (model 3).

When evaluating AMI (without taking CHD death into account) and adjusting for time-updated age and sex the HR for persons with type 2 diabetes compared with controls was 1.82 (95\% CI 1.79 to 1.85 ), and when additionally adjusting for diabetes duration and obtaining the HR at 8 years of duration it was 1.71 (95\% CI 1.68 to 1.74 ), and when additionally adjusting for country of birth, education level, and comorbidities at baseline (model 3) it was 1.58 (95\% CI, 1.56 to 1.61 ).

HRs for coronary events decreased with older age and were lower for men compared with women in all age groups (figure 1). In the fully adjusted model 3 , the HR decreased monotonically from 2.72 (95\% CI 2.50 to 2.96 ) among men aged $<55$ years to 1.17 (95\% CI 1.15 to 1.20 ) for men aged $\geq 75$ years. The corresponding HRs for women were $4.70(95 \%$ CI 4.00 to 5.54$)$ and $1.32(95 \%$ CI 1.28 to 1.35 ), respectively.

There was also a time interaction in which the adjusted HR for coronary events in patients with diabetes was lower during the last follow-up period (2005 or later) than during the initial 7 years of follow-up (HR in the initial 7 years: 1.57 (95\% CI 1.52 to 1.62 ); HR in the last 8 years' follow-up: 1.39 (95\% CI 1.37 to 1.41 ), $\mathrm{p}<0.001$ for interaction).

\section{Risk for coronary events related to glycaemic control and renal complications in the type 2 diabetes population compared with controls}

The adjusted HRs for AMI and death from CHD for time-updated mean HbAlc categories, albuminuria and eGFR are shown in tables 3 and 4. HRs for coronary events in the fully adjusted model among persons with type 2 diabetes were 1.19 (95\% CI 1.17 to $1.21, \mathrm{p}<0.001$ ) and 2.77 (95\% CI 2.62 to 2.93, p<0.001) with time-updated mean $\mathrm{HbAlC} \leq 6.9 \%(52 \mathrm{mmol} / \mathrm{mol})$ and $\mathrm{HbAlC}$ levels $\geq 9.7 \%$ ( $\geq 83 \mathrm{mmol} / \mathrm{mol}$ ), respectively, as compared with controls. When HbA1C was not time-updated (at baseline), the corresponding HRs were 1.22 (95\% CI 1.20-1.24) and 2.40 (95\% CI 2.29-2.51), respectively. In men and women with type 2 diabetes and time-updated mean $\mathrm{HbA} 1 \mathrm{C} \leq 6.9 \%$ ( $52 \mathrm{mmol} / \mathrm{mol})$, HRs for coronary events were 1.15 (95\% CI 1.13 to $1.18, \mathrm{p}<0.001)$ and 1.26 (95\% CI 1.22 to $1.30, \mathrm{p}<0.001$ ), respectively, as compared with controls.

Among patients with eGFR of $60-90 \mathrm{~mL} / \mathrm{min}$ and CKD stage 2, HRs for coronary events were 1.17 (95\% CI 1.15 to $1.19, \mathrm{p}<0.001$ ), and four times as high as that among controls $(4.25,95 \%$ CI 3.79 to $4.78, \mathrm{p}<0.001)$ with eGFR $<15 \mathrm{~mL} / \mathrm{min}$ or dialysis (ie, end-stage renal disease or CKD stage 5). In men and women with type 2 diabetes and time-updated mean HbAlc 6.9\% ( $\leq 52$ $\mathrm{mmol} / \mathrm{mol}$ ), normoalbuminuria and eGFR $\geq 60 \mathrm{~mL} / \mathrm{min}$, HRs for coronary events were 0.94 (95\% CI 0.90 to 0.98 , $\mathrm{p}=0.0014)$ and 0.98 (95\% CI 0.93 to $1.04, \mathrm{p}=0.56)$, respectively, compared with controls.

\section{Risk of AMI and CHD death by $10 \mathrm{mmol} / \mathrm{mol} \mathrm{HbA1c}$ increase}

The relationship between continuous time-updated mean $\mathrm{HbAlc}$ (per $1 \%(10 \mathrm{mmol} / \mathrm{mol})$ increase) and risk of CHD events was investigated among patients with type 2 diabetes. The HR for AMI and CHD death was 1.23 (95\% CI 1.22 to 1.24) when adjusted for age and sex, 1.21 (95\% CI 1.20 to 1.23 ) and 1.26 (95\% CI 1.24 to 1.27 ) for men and women respectively, and 1.19 (95\% CI 1.18 to 1.20) when adjusted for time-updated diabetes duration, education, birth in Sweden and comorbidities prior to baseline, 1.18 (95\% CI 1.16 to 1.19) and 1.21 (95\% CI 1.19 to 1.22) for men and women respectively. In further adjustments, models 3A-3D, the HRs for $1 \%$ increase in HbAlc on AMI and CHD death ranged between 1.171.23 for women and 1.16-1.18 for men.

\section{DISCUSSION}

The present population-based study involving more than 400000 individuals with type 2 diabetes from the Swedish NDR and more than 2 million matched controls showed an excess risk of AMI and death from CHD in type 2 diabetes of $67 \%$, which decreased to $42 \%$ after adjustment 
Table 3 Adjusted HRs for AMI or CHD death and 95\% Cls for time-updated mean HbA1c, albuminuria and eGFR categories versus the reference group examined by Cox regression

\section{HR (95\% Cl) P value}

\begin{tabular}{|c|c|c|c|}
\hline \multirow[b]{2}{*}{ AMI or CHD death } & \multicolumn{3}{|l|}{ HR (95\% CI) P value } \\
\hline & $\begin{array}{l}\text { Model } 3 \\
\text { All patients and controls }\end{array}$ & $\begin{array}{l}\text { Model } 3 a \\
\text { Male patients and } \\
\text { controls }\end{array}$ & $\begin{array}{l}\text { Model } 3 b \\
\text { Female patients and } \\
\text { controls }\end{array}$ \\
\hline $\begin{array}{l}\text { Type } 2 \text { diabetes versus controls } \\
\text { Time-updated DD=1 year (10th percentile) }\end{array}$ & 1.24 (1.22 to 1.26$)$ & $1.21(1.18$ to 1.24$)$ & 1.30 (1.26 to 1.33$)$ \\
\hline $\begin{array}{l}\text { Type } 2 \text { diabetes versus controls } \\
\text { Time-updated DD }=4 \text { years ( } 25 \text { th percentile) }\end{array}$ & $1.32(1.30$ to 1.34$)$ & $1.27(1.25$ to 1.30$)$ & 1.39 (1.35 to 1.43$)$ \\
\hline $\begin{array}{l}\text { Type } 2 \text { diabetes versus controls } \\
\text { Time-updated } \mathrm{DD}=8 \text { years ( } 50 \text { th percentile): main } \\
\text { results }\end{array}$ & $1.42(1.41$ to 1.44$)$ & $1.37(1.34$ to 1.39$)$ & $1.53(1.49$ to 1.56$)$ \\
\hline $\begin{array}{l}\text { Type } 2 \text { diabetes versus controls } \\
\text { Time-updated } D D=13 \text { years ( } 75 \text { th percentile) }\end{array}$ & $1.58(1.56$ to 1.60$)$ & 1.49 (1.47 to 1.52$)$ & $1.72(1.68$ to 1.75$)$ \\
\hline $\begin{array}{l}\text { Type } 2 \text { diabetes versus controls } \\
\text { Time-updated } D D=19 \text { years (90th percentile) }\end{array}$ & $1.78(1.75$ to 1.80$)$ & 1.66 (1.62 to 1.69$)$ & 1.98 (1.94 to 2.02) \\
\hline \multicolumn{4}{|c|}{ For a patient with type 2 diabetes with median diabetes duration ( 8 years) } \\
\hline Type 2 diabetes versus controls $\leq 2005$ & 1.57 (1.52 to 1.62$)$ & $1.52(1.46$ to 1.58$)$ & $1.66(1.58$ to 1.74$)$ \\
\hline $\begin{array}{l}\text { Type } 2 \text { diabetes versus controls } \\
>2005\end{array}$ & 1.39 (1.37 to 1.41) & 1.34 (1.31 to 1.36$)$ & $1.49(1.45$ to 1.53$)$ \\
\hline Time-updated mean HbA1c categories & $\begin{array}{l}\text { Events }(n)=142689 \\
\text { Subjects }(n)=2502026 \\
\text { Data used }=96.0 \%\end{array}$ & $\begin{array}{l}\text { Events }(n)=88143 \\
\text { Subjects }(n)=1354248 \\
\text { Data used }=96.4 \%\end{array}$ & $\begin{array}{l}\text { Events }(n)=54546 \\
\text { Subjects }(n)=1147778 \\
\text { Data used }=95.6 \%\end{array}$ \\
\hline Controls (reference) & 1.00 & 1.00 & 1.00 \\
\hline$\leq 6.9 \%(\leq 52 \mathrm{mmol} / \mathrm{mol})$ & $1.19(1.17$ to 1.21$)$ & 1.15 (1.13 to 1.18$)$ & $1.26(1.22$ to 1.30$)$ \\
\hline $7.0 \%-7.8 \%(53-62 \mathrm{mmol} / \mathrm{mol})$ & 1.51 (1.48 to 1.55$)$ & $1.44(1.40$ to 1.48$)$ & $1.65(1.59$ to 1.71$)$ \\
\hline $7.9 \%-8.7 \%$ (63-72 mmol/mol) & $1.91(1.85$ to 1.96$)$ & $1.79(1.72$ to 1.85$)$ & $2.10(2.01$ to 2.20$)$ \\
\hline $8.8 \%-9.6 \%(73-82 \mathrm{mmol} / \mathrm{mol})$ & 2.23 (2.14 to 2.33 ) & 2.09 (1.97 to 2.21) & 2.46 (2.30 to 2.64$)$ \\
\hline$\geq 9.7 \%$ ( $\geq 83 \mathrm{mmol} / \mathrm{mol})$ & 2.77 (2.62 to 2.93) & 2.54 (2.36 to 2.74$)$ & 3.10 (2.84 to 3.38$)$ \\
\hline Time-updated albuminuria categories & $\begin{array}{l}\text { Events }(n)=137903 \\
\text { Subjects }(n)=2447451 \\
\text { Data used }=93.9 \%\end{array}$ & $\begin{array}{l}\text { Events }(n)=85501 \\
\text { Subjects }(n)=1325008 \\
\text { Data used }=94.3 \%\end{array}$ & $\begin{array}{l}\text { Events }(n)=52402 \\
\text { Subjects }(n)=1122443 \\
\text { Data used }=93.5 \%\end{array}$ \\
\hline Controls (reference) & 1.00 & 1.00 & 1.00 \\
\hline Normoalbuminuria & $1.29(1.27$ to 1.31$)$ & $1.23(1.20$ to 1.26$)$ & 1.38 (1.34 to 1.42$)$ \\
\hline Microalbuminuria & $1.63(1.58$ to 1.68$)$ & $1.55(1.50$ to 1.60$)$ & $1.84(1.75$ to 1.93$)$ \\
\hline Macroalbuminuria & 2.08 (2.01 to 2.15$)$ & 2.00 (1.92 to 2.08$)$ & 2.40 (2.27 to 2.54$)$ \\
\hline CKD stage 5 & 4.20 (3.74 to 4.72$)$ & 3.96 (3.42 to 4.58$)$ & 4.74 (3.93 to 5.72$)$ \\
\hline Time-updated eGFR categories & $\begin{array}{l}\text { Events }(n)=137434 \\
\text { Subjects }(n)=2477771 \\
\text { Data used }=95.1 \%\end{array}$ & $\begin{array}{l}\text { Events }(n)=85066 \\
\text { Subjects }(n)=1341052 \\
\text { Data used }=95.4 \%\end{array}$ & $\begin{array}{l}\text { Events }(n)=52368 \\
\text { Subjects }(n)=1136719 \\
\text { Data used }=94.7 \%\end{array}$ \\
\hline Controls (reference) & 1.00 & 1.00 & 1.00 \\
\hline CKD stage $1(\mathrm{eGFR} \geq 90)$ & $1.55(1.51$ to 1.61$)$ & 1.44 (1.38 to 1.49$)$ & 1.89 (1.77 to 2.01$)$ \\
\hline CKD stage 2 (eGFR 60-89) & 1.17 (1.15 to 1.19$)$ & $1.13(1.10$ to 1.16$)$ & 1.28 (1.24 to 1.32$)$ \\
\hline CKD stage 3 (eGFR 30-59) & $1.46(1.43$ to 1.50$)$ & $1.45(1.40$ to 1.50$)$ & 1.47 (1.42 to 1.52$)$ \\
\hline CKD stage 4 (eGFR 15-29) & 2.37 (2.24 to 2.51$)$ & 2.26 (2.08 to 2.45$)$ & 2.37 (2.19 to 2.57$)$ \\
\hline CKD stage 5 (eGFR <15 or dialysis) & 4.25 (3.79 to 4.78$)$ & 3.97 (3.43 to 4.60$)$ & 4.91 (4.07 to 5.93) \\
\hline
\end{tabular}

Adjusted for time-updated age and sex (for all patient models), time-updated diabetes duration (centred at median 8 years), born in Sweden, maximum education level and baseline comorbidities (AF, CHD, HF, VD, stroke, cancer).

All comparisons have $p<0.0001$.

AF, atrial fibrillation; AMI, acute myocardial infarction; CHD, coronary heart disease; CKD, chronic kidney disease; DD, diabetes duration; HF, heart failure; VD, valve disease; eGFR, estimated glomerular filtration rate. 
Table 4 Adjusted HRs for AMI or CHD death and 95\% Cls for time-updated mean HbA1c categories together with albuminuria and eGFR versus the reference group examined by Cox regression

\begin{tabular}{|c|c|c|c|}
\hline \multirow[b]{2}{*}{ AMI or CHD death } & \multicolumn{3}{|l|}{ HR (95\% Cl) P value } \\
\hline & $\begin{array}{l}\text { Model } 3 \\
\text { All patients and } \\
\text { controls }\end{array}$ & $\begin{array}{l}\text { Model } 3 a \\
\text { Male patients and } \\
\text { controls }\end{array}$ & $\begin{array}{l}\text { Model } 3 b \\
\text { Female patients } \\
\text { and controls }\end{array}$ \\
\hline Time-updated mean HbA1c categories albuminuria and eGFR & $\begin{array}{l}\text { Events }(n)=136231 \\
\text { Subjects }(n)=2445866\end{array}$ & $\begin{array}{l}\text { Events }(n)=84382 \\
\text { Subjects }(n)=1323072\end{array}$ & $\begin{array}{l}\text { Events }(n)=51849 \\
\text { Subjects }(n)=1122794\end{array}$ \\
\hline Controls (reference) & 1.00 & 1.00 & 1.00 \\
\hline $7.0 \%-7.8 \%$ (53-62 mmol/mol):normoalbuminuria and eGFR $\geq 60$ & $\begin{array}{l}1.21(1.16 \text { to } 1.25) \\
<0.0001\end{array}$ & $\begin{array}{l}1.16(1.11 \text { to } 1.22) \\
<0.0001\end{array}$ & $\begin{array}{l}1.31(1.23 \text { to } 1.40) \\
<0.0001\end{array}$ \\
\hline $7.9 \%-8.7 \%$ (63-72 mmol/mol):normoalbuminuria and eGFR $\geq 60$ & $\begin{array}{l}1.63(1.54 \text { to } 1.72) \\
<0.0001\end{array}$ & $\begin{array}{l}1.51(1.41 \text { to } 1.62) \\
<0.0001\end{array}$ & $\begin{array}{l}1.87 \text { (1.71 to } 2.04) \\
<0.0001\end{array}$ \\
\hline$\leq 6.9 \%$ ( $\leq 52 \mathrm{mmol} / \mathrm{mol})$ :not normoalbuminuria or eGFR $<60$ & $\begin{array}{l}1.40(1.37 \text { to } 1.44) \\
<0.0001\end{array}$ & $\begin{array}{l}1.39(1.34 \text { to } 1.43) \\
<0.0001\end{array}$ & $\begin{array}{l}1.42(1.36 \text { to } 1.47) \\
<0.0001\end{array}$ \\
\hline $7.0 \%-7.8 \%$ (53-62 mmol/mol):not normoalbuminuria or eGFR $<60$ & $\begin{array}{l}1.70(1.65 \text { to } 1.75) \\
<0.0001\end{array}$ & $\begin{array}{l}1.65(1.58 \text { to } 1.71) \\
<0.0001\end{array}$ & $\begin{array}{l}1.78 \text { (1.69 to } 1.86) \\
<0.0001\end{array}$ \\
\hline $7.9 \%-8.7 \%$ (63-72 mmol/mol):not normoalbuminuria or eGFR $<60$ & $\begin{array}{l}2.11(2.03 \text { to } 2.20) \\
<0.0001\end{array}$ & $\begin{array}{l}2.04 \text { (1.94 to } 2.15) \\
<0.0001\end{array}$ & $\begin{array}{l}2.21 \text { (2.07 to } 2.35) \\
<0.0001\end{array}$ \\
\hline $8.8 \%-9.6 \%$ (73-82 mmol/mol):not normoalbuminuria or eGFR $<60$ & $\begin{array}{l}2.48 \text { (2.33 to } 2.63) \\
<0.0001\end{array}$ & $\begin{array}{l}2.41(2.23 \text { to } 2.60) \\
<0.0001\end{array}$ & $\begin{array}{l}2.56(2.33 \text { to } 2.81) \\
<0.0001\end{array}$ \\
\hline$\geq 9.7 \%$ ( $\geq 83 \mathrm{mmol} / \mathrm{mol}$ ): not normoalbuminuria or eGFR $<60$ & $\begin{array}{l}2.94 \text { (2.71 to } 3.19) \\
<0.0001\end{array}$ & $\begin{array}{l}2.77 \text { (2.49 to } 3.09) \\
<0.0001\end{array}$ & $\begin{array}{l}3.14 \text { (2.77 to } 3.56) \\
<0.0001\end{array}$ \\
\hline
\end{tabular}

Adjusted for time-updated age and sex (for all patient models), time-updated diabetes duration (centred at median 8 years), born in Sweden, maximum education level and baseline comorbidities (AF, CHD, HF, VD, stroke, cancer).

AF, atrial fibrillation; AMI, acute myocardial infarction; CHD, coronary heart disease; HF, heart failure; VD, valve disease; eGFR, estimated glomerular filtration rate.

for country of birth, diabetes duration, education level and comorbidities. Furthermore, the excess risk of AMI and CHD death at any age was higher for women with type 2 diabetes compared with men.

A previous meta-analysis of 64 cohorts ${ }^{19}$ including more than 800000 individuals showed that the relative risk for CHD associated with diabetes compared with no diabetes was 2.82 (95\% CI 2.35 to 3.38$)$ in women and $2.16(95 \%$ CI 1.82 to 2.56 ) in men.

In several studies ${ }^{20} 21$ where the risk of CHD was analysed separately in men and women, the effect of diabetes was greater in women than men. Although there was a higher absolute risk for AMI and CHD in men with type 2 diabetes, the higher relative risk in women may have been due to the superior survival of women without diabetes. A pooled analysis ${ }^{19}$ showed that the presence of diabetes conferred a $44 \%(95 \%$ CI $27 \%$ to $63 \%)$ greater excess risk of CHD in women compared with men. This greater excess coronary risk may be explained by biological gender differences that confer more adverse cardiovascular risk profiles among women than men with diabetes.
In our study the excess risk of AMI and CHD death was higher in individuals with type 2 diabetes with worsening glycaemic control and renal complications. Other studies have also found an association between renal complications and mortality. ${ }^{22}{ }^{23}$ However, higher relative risk for AMI and CHD death was found in younger patients, whereas absolute risk was higher in older patients.

The excess risk for AMI and CHD death in the fully adjusted model was lower compared with previous studies $^{56}$ and converged to that in the general population in both men and women with type 2 diabetes without prior AMI, on-target HbA1c and no renal complications. In two cohorts aged 50 years or older with type 2 diabetes from November 1986 to November 2008, higher mean HbAlc values were associated with increased risk of all-cause of mortality and cardiac events. ${ }^{24}$

A previous study ${ }^{25}$ showed the benefit of glucose lowering, assuming a 15\% reduction in the rate of cardiovascular events for every 1 percentage point reduction in HbAlc. The benefits of glycaemic treatment vary depending on patient age at diagnosis. 
Furthermore, reduced eGFR $\left(<60 \mathrm{~mL} / \mathrm{min} / 1.73 \mathrm{~m}^{2}\right)$ at baseline and during follow-up was associated with increased risk of incident CHD in patients with type 2 diabetes. ${ }^{26}$ A previous study ${ }^{3}$ showed that long-term HbA1c on target and absence of kidney disease are associated with low mortality risk. Recently, a large Swedish study ${ }^{27}$ involving more than 400000 patients with type 2 diabetes showed that individuals with on-target HbA1C, without renal complications and with normal blood pressure and lipid profiles appeared to have little or no excess risk of cardiovascular events as compared with the general population. In our study, the excess risk of coronary artery disease was evaluated in both men and women and the model was also adjusted for time-updated diabetes duration and comorbidities prior to baseline. Furthermore, unlike previous investigations, study covariates (HbA1c and eGFR) were time updated, thus all follow-up data were taken into account and opposed to only data at baseline.

The excess risk of AMI and CHD death in persons with type 2 diabetes diminished over time and was lower during the last eight calendar years of the study than during the first 7 years of follow-up.

Integrated diabetes care, improved patient education and recent advances in prevention, treatment and management can effectively help patients cope with the vast array of complications that can arise from diabetes and, therefore, may have reduced rates of cardiovascular complications among patients.

Screening patients with type 2 diabetes for cardiovascular risk is an important strategy for cardiovascular events. $^{28}$

Additionally, previous studies ${ }^{29} 30$ have shown that intensive glycaemic control over long-time period is associated with reduced risk of major cardiovascular events and total mortality.

Our study implies that good glycemic control and avoiding renal complication are essential to reduce risk for coronary artery events in patients with type 2 diabetes. The current results thus support diabetes guidelines advocating early detection of diabetes, good glycaemic control, and encouraging use of lipid-lowering and antihypertensive medications. CVD risk will likely continue to converge to that in the general population if risk factors according to guidelines can be obtained in a broader population of type 2 diabetes. The greater excess risk of coronary artery disease among women with diabetes needs to be further investigated.

Furthermore, future diabetes care should also focus on reducing cardiovascular risk in patients who have existing renal complications and this group of patients should be treated more aggressively with regard to lipid-lowering agents, smoking cessation and lifestyle interventions.

Strengths of the current study include a large population of patients with type 2 diabetes and use of NDR data allowing for comprehensive understanding and ascertainment of information. The epidemiological definitions of type 2 diabetes and outcomes are well validated. For most patients, at least one measurement of HbA1c, grade of albuminuria and eGFR was collected. More than 2 million controls were included, and information on education level and coexisting diseases was available over a period of at least 11 years before start of follow-up.

There are several limitations of this study. First, some variables that may be associated with AMI and CHD death were not available on an individual level for controls. Second, residual bias could persist owing to unmeasured or imprecisely measured potential confounding factors (eg, dietary intake and physical activity, respectively). Third, our data were derived from a higher income country with equitable access to diabetes care at low cost to patients.

In summary, the excess risk of AMI and CHD death in patients with type 2 diabetes without prior AMI was higher than controls, and primarily in those with worsening glucose control and renal function, although it converged to that in the general population in patients with HbA1c on target and without renal complications. Higher excess risk for AMI and CHD death was also found in women than men with diabetes.

\section{Author affiliations}

${ }^{1}$ Department of Molecular and Clinical Medicine, Institute of Medicine, University of Gothenburg, Gothenburg, Sweden

${ }^{2}$ Department of Medicine, NU-Hospital Organization, Trollhättan and Uddevalla, Sweden

${ }^{3}$ Centre of Registers in region Västra Götaland, Gothenburg, Sweden

${ }^{4}$ Statistiska Konsultgruppen, Gothenburg, Sweden

${ }^{5}$ Department of Ophthalmology, Institute of Neuroscience and Physiology,

Sahlgrenska Academy, University of Gothenburg, Gothenburg, Sweden

${ }^{6}$ Health Metrics Sahlgrenska Academy, University of Gothenburg, Gothenburg, Sweden

Acknowledgements We thank all the data-collecting clinicians and staff at the National Diabetes Register, and Joseph W Murphy for editorial assistance.

Contributors MT and ML drafted the manuscript, with AR revising it for important intellectual content. AP performed the statistical analysis. SG and AMS contributed to data collection. All authors contributed to the study design, data interpretation and to manuscript drafting and approval. ML is the guarantor of this work and, as such, had full access to all data in the study and takes responsibility for the integrity of data and accuracy of the analysis.

Funding The study was financed by grants from the Swedish Society of Medicine and the Health and Medical Care Committee of the Regional Executive Board, Region Västra Götaland, Sweden, the Swedish State under the Agreement Concerning Research and Education of Doctors; the Swedish Heart and Lung Foundation; and the Swedish Research Council (SIMSAM).

Competing interests None declared.ML has received honoraria or been consultant for Astra Zeneca, DexCom, Eli Lilly, MSD, Rubin Medical and Novonordisk and received research grants from Astra Zeneca, DexCom and Novonordisk.

Patient consent for publication Not required.

Ethics approval Regional Ethics Review Board at University of Gothenburg, Sweden.

Provenance and peer review Not commissioned; externally peer reviewed.

Data sharing statement All data relevant to the study are included in the article or uploaded as supplementary information.

Open access This is an open access article distributed in accordance with the Creative Commons Attribution Non Commercial (CC BY-NC 4.0) license, which 
permits others to distribute, remix, adapt, build upon this work non-commercially, and license their derivative works on different terms, provided the original work is properly cited, appropriate credit is given, any changes made indicated, and the use is non-commercial. See: http://creativecommons.org/licenses/by-nc/4.0/.

\section{REFERENCES}

1. Zhou B, Lu Y, Haijfathalian K, et al. Worldwide trends in diabetes since 1980: a pooled analysis of 751 population-based studies with 4.4 million participants. The Lancet 2016;387:1513-30.

2. Whiting DR, Guariguata L, Weil C, et al. IDF diabetes atlas: global estimates of the prevalence of diabetes for 2011 and 2030. Diabetes Res Clin Pract 2011;94:311-21.

3. Tancredi M, Rosengren A, Svensson A-M, et al. Excess mortality among persons with type 2 diabetes. $N$ Engl J Med 2015;373:1720-32.

4. Grundy SM, Benjamin IJ, Burke GL, et al. Diabetes and cardiovascular disease: a statement for healthcare professionals from the American Heart Association. Circulation 1999:100:1134-46.

5. Sarwar N, Gao P, Seshasai SRK, et al. Diabetes mellitus, fasting blood glucose concentration, and risk of vascular disease: a collaborative meta-analysis of 102 prospective studies. Lancet 2010;375:2215-22.

6. Di Angelantonio E, Kaptoge S, Wormser D, et al. Association of cardiometabolic multimorbidity with mortality. JAMA 2015;314:52-60.

7. Rawshani A, Rawshani A, Franzén S, et al. Mortality and cardiovascular disease in type 1 and type 2 diabetes. N Engl J Med 2017;376:1407-18.

8. Peters SAE, Huxley RR, Sattar N, et al. Sex differences in the excess risk of cardiovascular diseases associated with type 2 diabetes: potential explanations and clinical implications. Curr Cardiovasc Risk Rep 2015;9.

9. Norhammar A. Diabetes and cardiovascular mortality: the impact of sex. Lancet Diabetes Endocrinol 2018;6:517-9.

10. Singh GM, Danaei G, Farzadfar F, et al. The age-specific quantitative effects of metabolic risk factors on cardiovascular diseases and diabetes: a pooled analysis. PLoS One 2013;8:e65174.

11. Eeg-Olofsson K, Zethelius B, Gudbjörnsdottir S, et al. Considerably decreased risk of cardiovascular disease with combined reductions in $\mathrm{HbA1c}$, blood pressure and blood lipids in type 2 diabetes: report from the Swedish national diabetes Register. Diab Vasc Dis Res 2016;13:268-77.

12. Gudbjörnsdottir S, Cederholm J, Nilsson PM, et al. The national diabetes Register in Sweden: an implementation of the St. Vincent Declaration for quality improvement in diabetes care. Diabetes Care 2003;26:1270-6.

13. Lind M, Svensson A-M, Kosiborod M, et al. Glycemic contro and excess mortality in type 1 diabetes. $N$ Engl J Med 2014;371:1972-82.

14. Olén $\mathrm{O}$, Bihagen $\mathrm{E}$, Rasmussen $\mathrm{F}$, et al. Socioeconomic position and education in patients with coeliac disease. Dig Liver Dis 2012;44:471-6.

15. Wettermark B, Hammar N, MichaelFored C, et al. The new Swedish prescribed drug Register-Opportunities for pharmacoepidemiological research and experience from the first six months. Pharmacoepidemiol Drug Saf 2007;16:726-35.

16. Lind $M$, Odén A, Fahlén $M$, et al. A systematic review of HbA1c variables used in the study of diabetic complications. Diabetes \& Metabolic Syndrome: Clinical Research \& Reviews 2008;2:282-93.

17. Hoelzel W, Weykamp C, Jeppsson J-O, et al. IFCC reference system for measurement of hemoglobin A1c in human blood and the National standardization schemes in the United States, Japan, and Sweden: a method-comparison study. Clin Chem 2004:50:e74:166-74.

18. Targher G, Zoppini G, Mantovani W, et al. Comparison of two creatinine-based estimating equations in predicting all-cause and cardiovascular mortality in patients with type 2 diabetes. Diabetes Care 2012;35:2347-53.

19. Peters SAE, Huxley RR, Woodward M. Diabetes as risk factor for incident coronary heart disease in women compared with men: a systematic review and meta-analysis of 64 cohorts including 858,507 individuals and 28,203 coronary events. Diabetologia 2014;57:1542-51.

20. Lee WL, Cheung AM, Cape D, et al. Impact of diabetes on coronary artery disease in women and men: a meta-analysis of prospective studies. Diabetes Care 2000;23:962-8.

21. Natarajan S, Liao Y, Cao G, et al. Sex differences in risk for coronary heart disease mortality associated with diabetes and established coronary heart disease. Arch Intern Med 2003;163.

22. So WY, Kong APS, Ma RCW, et al. Glomerular filtration rate, cardiorenal end points, and all-cause mortality in type 2 diabetic patients. Diabetes Care 2006;29:2046-52.

23. Fox CS, Matsushita K, Woodward M, et al. Associations of kidney disease measures with mortality and end-stage renal disease in individuals with and without diabetes: a meta-analysis. Lancet 2012;380:1662-73.

24. Currie CJ, Peters JR, Tynan A, et al. Survival as a function of $\mathrm{HbA}(1 \mathrm{c})$ in people with type 2 diabetes: a retrospective cohort study. Lancet 2010;375:481-9.

25. Vijan S, Sussman JB, Yudkin JS, et al. Effect of patients' risks and preferences on health gains with plasma glucose level lowering in type 2 diabetes mellitus. JAMA Intern Med 2014;174:1227-34.

26. Wang Y, Katzmarzyk PT, Horswell R, et al. Kidney function and the risk of cardiovascular disease in patients with type 2 diabetes. Kidney Int 2014;85:1192-9.

27. Rawshani A, Rawshani A, Franzén S, et al. Risk factors, mortality, and cardiovascular outcomes in patients with type 2 diabetes. $N$ Engl J Med 2018;379:633-44.

28. Simmons RK, Griffin SJ, Lauritzen T, et al. Effect of screening for type 2 diabetes on risk of cardiovascular disease and mortality: a controlled trial among 139,075 individuals diagnosed with diabetes in Denmark between 2001 and 2009. Diabetologia 2017;60:2192-9.

29. Fang $\mathrm{H}-\mathrm{J}$, Zhou $\mathrm{Y}-\mathrm{H}$, Tian $\mathrm{Y}-\mathrm{J}$, et al. Effects of intensive glucose lowering in treatment of type 2 diabetes mellitus on cardiovascular outcomes: a meta-analysis of data from 58,160 patients in 13 randomized controlled trials. Int J Cardiol 2016;218:50-8.

30. UK Prospective Diabetes Study (UKPDS) group. Intensive bloodglucose control with sulphonylureas or insulin compared with conventional treatment and risk of complications in patients with type 2 diabetes (UKPDS33). Lancet 1998;352:837-53. 